\title{
Estimated Platelets Measurement
}

National Cancer Institute

\section{Source}

National Cancer Institute. Estimated Platelets Measurement. NCI Thesaurus. Code C135440.

The estimated amount of platelets in a biological sample. 